\title{
AN EXTRACTION TECHNIQUE FOR THE ESTIMATION OF EVANS BLUE IN PLASMA
}

\author{
BY \\ MICHAEL HOBSLEY AND ERNEST D. DEW \\ From the Department of Surgical Studies, Middlesex Hospital, and the Institute of Clinical \\ Research, Middlesex Hospital Medical School, London
}

(RECEIVED FOR PUBLICATION FEBRUARY 5, 1958)

The dye-dilution method for the determination of plasma volume presents several problems, one of which is the estimation of dye concentration in plasma. It is with this problem that the present paper is primarily concerned.

The most frequently used dye is Evans blue, T 1824. The colorimetric estimation of this dye in plasma is open to a number of possible errors, particularly those introduced by opacity of the plasma and by the haemolysis of blood samples. Recently it has become possible quantitatively to extract Evans blue from plasma for estimation in watery solution (Allen and Orahovats, 1948 ; Allen, 1951 ; Korner, Morris, and Courtice, 1954 ; Bedwell, Patterson, and Swale, 1955).

As a result of considerable experience with Korner, Morris, and Courtice's method, it has become apparent that certain details of technique are of critical importance. The purpose of this article is to describe a technique that has been found to give satisfactory results, with regard both to speed and to accuracy.

\section{Method}

Reagents.-The following are required :

Evans blue, $0.5 \mathrm{~g} . / 100 \mathrm{ml}$., in distilled water (I.C.I.). Sodium chloride, 0.9 g. $/ 100 \mathrm{ml}$.

Cellulose tissues ("kleenex"), double-thickness sheets of size $21 \frac{1}{2} \times 17 \mathrm{~cm}$.

Teepol L (Shell Chemicals).

Solvent ether B.P.

$50 \%$ aqueous acetone, made by mixing equal volumes of acetone and distilled water.

Apparatus.-A measure for pulp (capacity $1 \mathrm{ml}$.) consists of a cylinder of brass rod, hollowed out to a maximum depth of $7 / 16$ in. by a drill of $\frac{1}{2}$ in. diameter having a conical head $\frac{1}{8}$ in. deep.

Porcelain Gooch crucibles of $8 \mathrm{ml}$. capacity, with perforated bottoms $1.5 \mathrm{~cm}$. in diameter, and fitted with suitable rubber seals.

A Buchner flask.

Glass filter funnels, each of 2 in. diameter.
Stoppered volumetric flasks of $10 \mathrm{ml}$. capacity (E-Mil wide-necked flasks were found to be the most suitable).

A spectrophotometer reading at $610 \mathrm{~m} \mu$ : the instrument used in this work has been the "unicam" spectrophotometer SP 500, with $1 \mathrm{~cm}$. fused glass cells.

Technique.-A $0.5 \%$ Evans blue solution in distilled water is injected intravenously in dosage depending on the subject's weight (about $0.075 \mathrm{~g}$./ $\mathrm{kg}$.), and samples of venous blood are removed without stasis at suitable intervals. Dry heparin is used as an anticoagulant. The blood samples are centrifuged and the plasma separated.

Teepol, $0.5 \mathrm{ml}$., is added to $1 \mathrm{ml}$. of the plasma in a test-tube, and the mixture shaken. It has now to be passed through an adsorption column, which is used in the form of a shallow pad. The pad is prepared in the following manner. A double sheet of " kleenex" tissue, $21 \frac{1}{2} \times 17 \mathrm{~cm}$., is cut into $1-2 \mathrm{~cm}$. squares and placed in a conical flask. Then $27 \mathrm{ml}$. of $0.9 \% \mathrm{NaCl}$ is added and the flask shaken until a homogeneous pulp is obtained, leaving about $5 \mathrm{ml}$. of supernatant saline. Vigorous shaking by hand for five minutes will be found to be adequate. A sufficient quantity of pulp is separated to the neck of the flask and excess fluid allowed to drain from it down the inside of the flask for a few seconds. Small portions of this drained pulp are transferred to the measure of $1 \mathrm{ml}$. capacity until it is filled levelly to the brim. During the filling of the measure no pressure is used to pack down the pad, but any excess fluid coming to the surface is decanted. The quantity of pulp so obtained is turned out into a perforated porcelain Gooch crucible. The pulp is spread evenly over the bottom of the crucible and tamped down with the end of a glass rod, using only the lightest pressure and paying special attention to the periphery. A well-prepared pad will look homogeneous when the crucible is held up to the light. It is then ready to use.

The plasma-" teepol " mixture is transferred to the prepared crucible (which rests conveniently in a filter funnel) and passes through the pad. It is important that no suction be used at this stage. The first few 
drops of filtrate may be used to wash the residue in the test-tube into the crucible, or $0.9 \%$ sodium chloride may be used for this purpose. The former technique is convenient, but not necessary, because even the first few drops have been cleared of Evans blue. When no free fluid remains in the crucible it is transferred to the neck of the suction flask and the pad is washed with $5 \mathrm{ml}$. saline, $5 \mathrm{ml}$. ether, and then $5 \mathrm{ml}$. saline, using gentle suction. By now the pad is coloured a pure blue and is ready for the process of elution. This is carried out with about $9 \mathrm{ml}$.* $50 \%$ acetone into a $10 \mathrm{ml}$. flask, again with the crucible resting in a filter funnel, and then the contents of the flasks are made up to the mark with more of the aqueous acetone. The optical density of this solution of Evans blue is determined spectrophotometrically at a wavelength of $610 \mathrm{~m} \mu$, and compared with that of a known standard.

Preparation of the Standard.-About $0.2 \mathrm{~g}$. of the Evans blue from the same ampoule used for the injection is, with an accuracy of $1 \%$, weighed into a $100 \mathrm{ml}$. flask and made up to the mark with $0.9 \%$ sodium chloride solution. Of this solution, $1 \mathrm{ml}$. is mixed with $0.5 \mathrm{ml}$. of "teepol" and passed through the same process as the unknown sample. However, unless extreme accuracy is required a simpler technique is adequate, namely, $1 \mathrm{ml}$. of the $0.5 \%$ Evans blue is diluted to $500 \mathrm{ml}$. in distilled water, and $1 \mathrm{ml}$. of this solution made up to $10 \mathrm{ml}$. with $50 \%$ acetone and its optical density directly determined. The loss of accuracy caused by not passing the standard through the extraction process is discussed later.

\section{Discussion and Results}

Both Allen (1951) and Korner et al. (1954) suggest that the dyed plasma should, after mixing with the detergent, be allowed to stand for five minutes. An experiment to determine whether this pause is necessary was performed. Thirty different samples of dyed plasma were estimated, each in duplicate. The spectrophotometer readings of all 60 samples averaged 0.072 (range $0.062-0.083$ ). For one set of samples the fiveminute wait was included in the process, but for the duplicate set it was not included. The spectrophotometer readings of the pairs were identical in five pairs, differed by 0.001 in 18 pairs, by 0.002 in five pairs, by 0.003 in one pair, and by 0.005 in the remaining pair. The difference between the means of the two series was 0.0006 . It was concluded that the five-minute pause is unnecessary.

With Allen's $1 \mathrm{~cm}$. column, the process of elution takes half an hour or more. Korner et al. claim greater rapidity for their technique but give no details of the preparation of their column. The cellulose pad described above gives rapid

* Direct experiment has shown that Evans blue, in the range of quantities used in this work, is always completely eluted from the pad by $7 \mathrm{ml}$. of the aqeuous acetone. filtration and elution but adequately prevents loss 은 of unadsorbed dye during filtration. The size of $\vec{F}$ the pad is critical. Too thick a pad greatly slows the procedure of elution, while too thin a pad gives an incomplete extraction. Table I illustrates these two points. It must be stressed that at no

TABLE I

EFFECT OF SIZE OF PAD

\begin{tabular}{|c|c|c|c|c|c|c|}
\hline & & & \multirow{2}{*}{$\begin{array}{c}\text { Standard } \\
\text { (Saline } \\
\text { Un- } \\
\text { extracted) }\end{array}$} & \multicolumn{3}{|c|}{$\begin{array}{c}\text { Evans Blue Plasma Extracted } \\
\text { with Pad of }\end{array}$} \\
\hline & & & & $\underset{\text { Size }}{\text { Half }}$ & $\begin{array}{l}\text { Full } \\
\text { Size }\end{array}$ & $\begin{array}{c}\text { Double } \\
\text { Size }\end{array}$ \\
\hline Density & & . & $\begin{array}{l}0.054 \\
0.054 \\
0.055\end{array}$ & $\begin{array}{l}0.049 \\
0.050 \\
0.049 \\
0.050 \\
0.023\end{array}$ & $\begin{array}{l}0.053 \\
0.051 \\
0.052 \\
0.053 \\
0.052\end{array}$ & $\begin{array}{l}0.054 \\
0.056 \\
0.054 \\
0.053 \\
0.053\end{array}$ \\
\hline \multicolumn{3}{|c|}{$\begin{array}{l}\text { Average duration of } \\
\text { elution (min.) }\end{array}$} & - & - & $14 \cdot 2$ & $24 \cdot 5$ \\
\hline
\end{tabular}

stage should water (as opposed to saline or $\mathbb{D}$ plasma) be allowed to come in contact with the $\mathbb{\mathbb { D }}$ pad, as this alters its texture and reduces its $\frac{3}{0}$ capacity to absorb Evans blue.

The Evans blue used (I.C.I.) has been made up $\vec{\varphi}$ in $10 \mathrm{ml}$. ampoules by the hospital pharmos of ceutical department. The absorption spectrum of the preparation has a narrow peak, at a wave length of $610 \mathrm{~m} \mu$. All samples give an adequately linear relationship between absorption and concentration over the range employed, but the exact values differ slightly from batch to batch, and very occasionally from ampoule to ampoule. For this

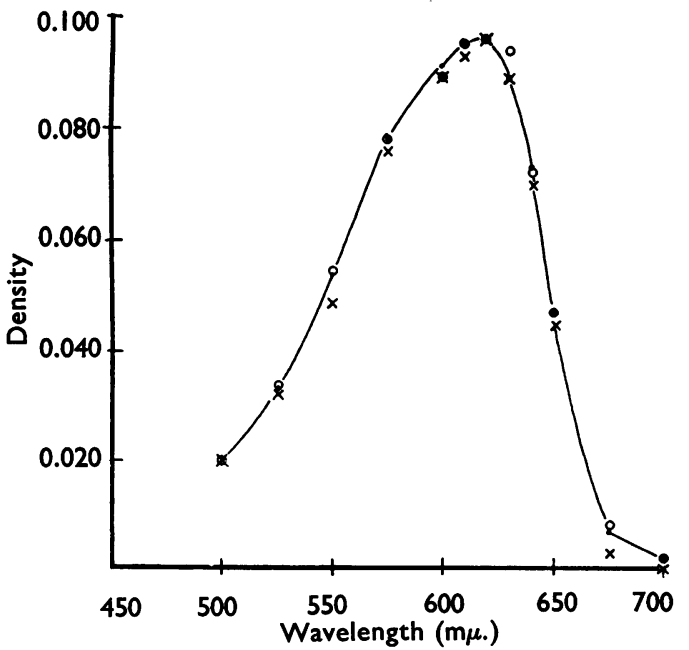

FIG. 1.-Whether in water, in saline, or extracted from plasma, the light-absorption spectrum of Evans blue is unaffected. $=$ Evans blue in water. $\mathbf{O}=$ Evans blue in saline. $\mathbf{X}=$ Evans blue extracted from plasma. 
reason a direct comparison is always made with a standard from the ampoule used for injection.

The process of adsorption and elution makes little difference to the light-absorption spectrum of the Evans blue, a fact that suggests that the dye remains unchanged in structure (Fig. 1). The Evans blue was not tested for quantity of impurity by the differential elution method of Leeson and Reeve (1949), but their statement that the I.C.I. product is satisfactory from this point of view was accepted in view of the indirect evidence of the absorption curves. Note also that whether the Evans blue is dissolved in water or in $0.9 \%$ saline makes no significant difference to the spectrum, or to the density of any given dose of the dye.

Several formal experiments on extraction rates have been carried out. One is summarized in Table II. Three solutions of Evans blue, in water, in $0.9 \%$ sodium chloride, and in plasma were

TABLE II

EXTRACTION RATES

\begin{tabular}{|c|c|c|c|c|c|c|}
\hline \multirow{2}{*}{\multicolumn{4}{|c|}{$\begin{array}{c}\text { Solution } \\
(1 \cdot 5 \mu \mathrm{g} . / \mathrm{ml} \text {. Evans Blue })\end{array}$}} & \multirow{3}{*}{$\begin{array}{c}\text { Density } \\
0.099\end{array}$} & \multicolumn{2}{|c|}{ Extraction Rate } \\
\hline & & & & & \multirow{2}{*}{$\frac{\% \mathrm{~A}}{-}$} & \multirow{2}{*}{$\frac{\% \mathrm{~B}}{-}$} \\
\hline In water (A) & $\ldots$ & $\ldots$ & $\ldots$ & & & \\
\hline \multicolumn{3}{|c|}{ In saline, extracted (B) } & . & $\begin{array}{l}0.093 \\
0.096 \\
0.094\end{array}$ & $\begin{array}{l}94 \\
97 \\
95\end{array}$ & E \\
\hline In plasma, ex & acted & .. & . & $\begin{array}{l}0.094 \\
0.095 \\
0.094 \\
0.092 \\
0.090\end{array}$ & $\begin{array}{l}95 \\
96 \\
95 \\
93 \\
91\end{array}$ & $\begin{array}{r}99 \\
100 \\
99 \\
97 \\
95\end{array}$ \\
\hline
\end{tabular}

made up gravimetrically. One millimetre of the aqueous solution, made up to $10 \mathrm{ml}$. with $50 \%$ acetone, read 0.099 . Three $1-\mathrm{ml}$. portions of the saline solution were passed through the whole procedure and gave readings from 94 to $97 \%$ of the unextracted Evans blue. Five 1-ml. portions of the plasma-Evans blue solution, similarly extracted, gave readings varying between 95 and $100 \%$ of that given by the extracted saline standard.

It will be noted that the passage of dye through the pad, even in saline solution, results in a definite loss of about $5 \%$ of the Evans blue. This loss is about $5 \%$ for any concentration of Evans blue in the range employed. Thus Fig. 2 shows the results of an experiment in which two solutions of Evans blue, of strengths $1 \mu \mathrm{g}$. and $2 \mu \mathrm{g}$. per ml., were extracted from saline and from plasma, and their optical densities compared with those of similar (unextracted) solutions in water.

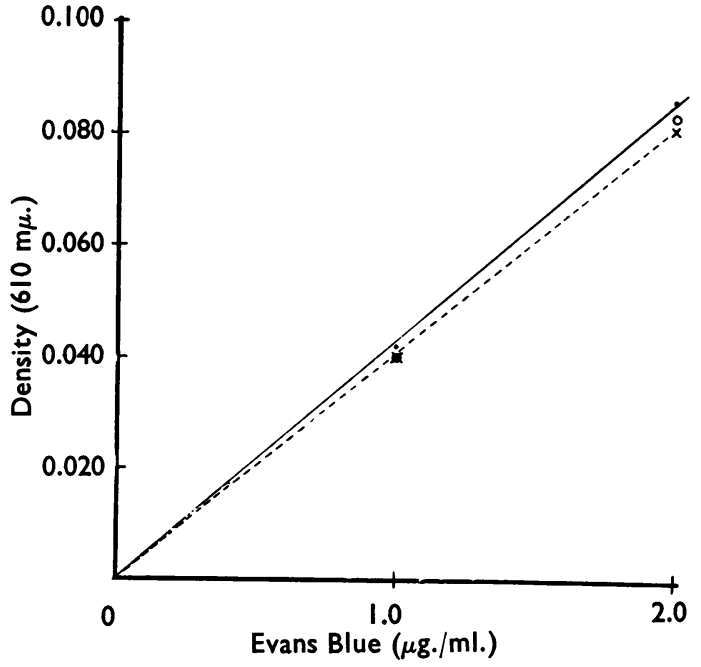

FIG. 2.-A loss of about $5 \%$ is incurred in passing dye through the pad, whether in saline or in plasma. $\longrightarrow$ Evans blue in water. 0 - . - 0 Evans blue in saline through pad. $\mathbf{X}---\mathbf{X}$ Evans blue in plasma through pad.

However, the extraction rate from plasma, as compared with that from saline, is $95-100 \%$ (usually at least $97 \%$ ). The potential error due to passage through the pad is automatically excluded in the method as described above, by making the standard up in saline and passing it through the pad. Alternatively, if the greatest accuracy is not required, and the aqueous unextracted standard is used, it would be sufficient to subtract $5 \%$ from the plasma volume calculated on the basis of this standard. These results were found not to be affected by lipaemia, haemolysis, or excessive bilirubinaemia of the plasma sample.

During the past two years a large number of estimations of Evans blue concentrations in plasma have been made on duplicate samples, and four different operators have been involved. Table III analyses the results of 419 such duplicate

TABLE III

RESULTS IN 419 DUPLICATE ESTIMATIONS

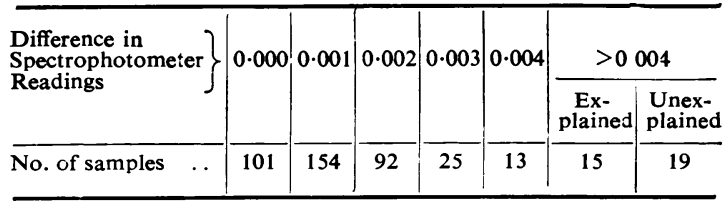

estimations. In 347 cases $(83 \%)$ the spectrophotometer readings differed by 0.002 or less, i.e., a percentage difference of only 2 to $3 \%$. In a further 38 cases $(9 \%)$ the difference between the duplicate readings, $0.003-0.004$, was still less than 
$5 \%$. As in this region cf its scale the spectrophotometer is calibrated only by 0.005 and finer readings must be made by eye, these results are considered satisfactory. Greater discrepancies were observed in 34 cases $(8 \%)$, but in 15 of these the causative error of manipulation had already been appreciated or was discovered in immediate retrospect. The remaining 19 were unexplained and must be considered a failure of the method: though, as it has been shown that the usual factors making difficult the estimation of Evans blue in plasma do not affect this method, it is considered likely that here too the errors involved were purely manipulative in nature.

The clinical value of any method for blood volume estimation is in inverse proportion to the time taken to complete the estimation. With the method described here, the estimation of a blood sample for its Evans blue content will be complete by the time a reliable reading of the haematocrit (say 30 minutes for spinning) has been obtained.

\section{Summary}

A technique for the estimation of Evans blue in plasma is described. The dye is adsorbed on to a small pad of cellulose pulped in $0.9 \%$ sodium chloride, which is then washed with saline, ether, and saline again, and extracted with $50 \%$ aque sus acetone.

Evidence is presented for the accuracy of the method, on the basis both of laboratcry experiments and of day-to-day experience with the method.

Our thanks are due to Dr. L. MacDonald, and to Dr. S. T. H. H. Pilbeam and Dr. E. T. Knudsen, of the Courtauld Institute of Biochemistry, who did valuable early studies with the technique, and to $\mathrm{Mr}$. L. P. Le Quesne for his kind collaboration throughout.

\section{REFERENCES}

Allen, T. H. (1951). Proc. Soc. exp. Biol. (N.Y.), 76, 145.

and Orahovats, P. D. (1948). Amer. J. Physiol., 154, 27.

Bedwell, G. A., Patterson, J., and Swale, J. (1955). J. clin. Path., 8, 61. Korner, P. I., Morris, B., and Courtice, F. C. (1954). Aust. J. exp Biol. med. Sci., 32, 301 .

Leeson, D., and Reeve, E. B. (1949). J. Physiol. (Lond.), $103,170$. 